\title{
Emptying Operation of Water Supply Networks
}

\author{
Oscar E. Coronado-Hernández ${ }^{1,2, *}$ (1) , Vicente S. Fuertes-Miquel ${ }^{2}\left[\right.$ (]) and Fredy N. Angulo-Hernández ${ }^{3}$ \\ 1 Facultad de Ingeniería, Universidad Tecnológica de Bolívar, Cartagena 131001, Colombia \\ 2 Departamento de Ingeniería Hidráulica y Medio Ambiente, Universitat Politècnica de València, \\ Valencia 46022, Spain; vfuertes@upv.es \\ 3 Aguas de Cartagena, Gerencia Técnica, Cartagena 130002, Colombia; fangulo@acuacar.com \\ * Correspondence: ocoronado@utb.edu.co; Tel.: +57-301-371-5398
}

Received: 13 November 2017; Accepted: 25 December 2017; Published: 29 December 2017

\begin{abstract}
Recently, emptying processes have been studied in experimental facilities in pipelines, but there is a lack regarding applications in actual pipelines, which permits establishing the risk of collapse because of sub-atmospheric pressure occurrence. This research presents a mathematical model to simulate the emptying process of water supply networks, and the application to a water emptying pipeline with nominal diameter of $1000 \mathrm{~mm}$ and $578 \mathrm{~m}$ long which is located on the southern of Cartagena, Bolívar Deparment, Colombia. In the application, both pipes and the air valve data manufacturer were considered. The behavior of all hydraulic and thermodynamic variables is considered. Results show that is crucial to know sub-atmospheric pressure values to prevent the collapse of the pipeline. The application of the mathematical model confirms that the hydraulic system is well designed depending on air valve sizes and maneuvering of drain valve.
\end{abstract}

Keywords: air-water; air valves; draining; emptying; transient flow; pipelines

\section{Introduction}

Trapped air can be introduced in water supply networks affecting the water behaviour during operational stages [1,2]. If trapped air is compressed, pressure surges occur [3,4]; in contrast, when it is expanded, then negative pressures are reached [5]. To avoid these situations, air valves should be installed along pipe systems since these devices relieve transient events through expelled/admitted air $[6,7]$.

Researchers have analyzed the consequences of transient events in pipelines in the following situations: during the filling process $[3,4,8,9]$, at pumping stations $[10,11]$, analyzing the propagation of air pockets [12], in valve closures [11], and by using protection devices [13,14]. The authors have developed a mathematical model to analyze the emptying process using experimental facilities $[5,15]$, which was validated for a single pipe at the Universitat Politècnica de València, Spain [15] and for a pipeline of irregular profile at the University of Lisbon, Portugal [5]. The main hydraulic and thermodynamic variables (absolute pressure, water velocity, and length of the emptying columns) were measured during the experiments. Figure 1 presents the used experimental facilities.

However, there is a lack regarding the application of the emptying process in actual pipelines that can be used for engineers to plan the process. In water supply networks, emptying maneuvers are required [5]. Knowing the behavior of transient flow, both water and air phase are important in order to simulate the emptying process; this is because the water flow will be replaced by the air flow. The emptying process starts when drain valves are opened, and trapped air pockets are immediately expanded and values of sub-atmospheric pressure are reached. Water velocities should be varied from 0.3 to $0.6 \mathrm{~m} / \mathrm{s}$ to do an appropriate operation [7], and air valves for vacuum protection should be installed adequately along of pipelines [5,15]. Air valves should open to admit an adequate quantity of air flow into the installation with a similar ratio than water flow in order to prevent sub-atmospheric 
pressure conditions. A maximum differential pressure of $34 \mathrm{kPa}$ ( $5 \mathrm{psi}$ ) is recommended during the transient event [6]. However, if air valves are not installed or failed during the process, then the hydraulic system can collapse depending on the values of the sub-atmospheric pressure, and the installation conditions (e.g., soil in natural conditions, type of backfill, and cover depth).
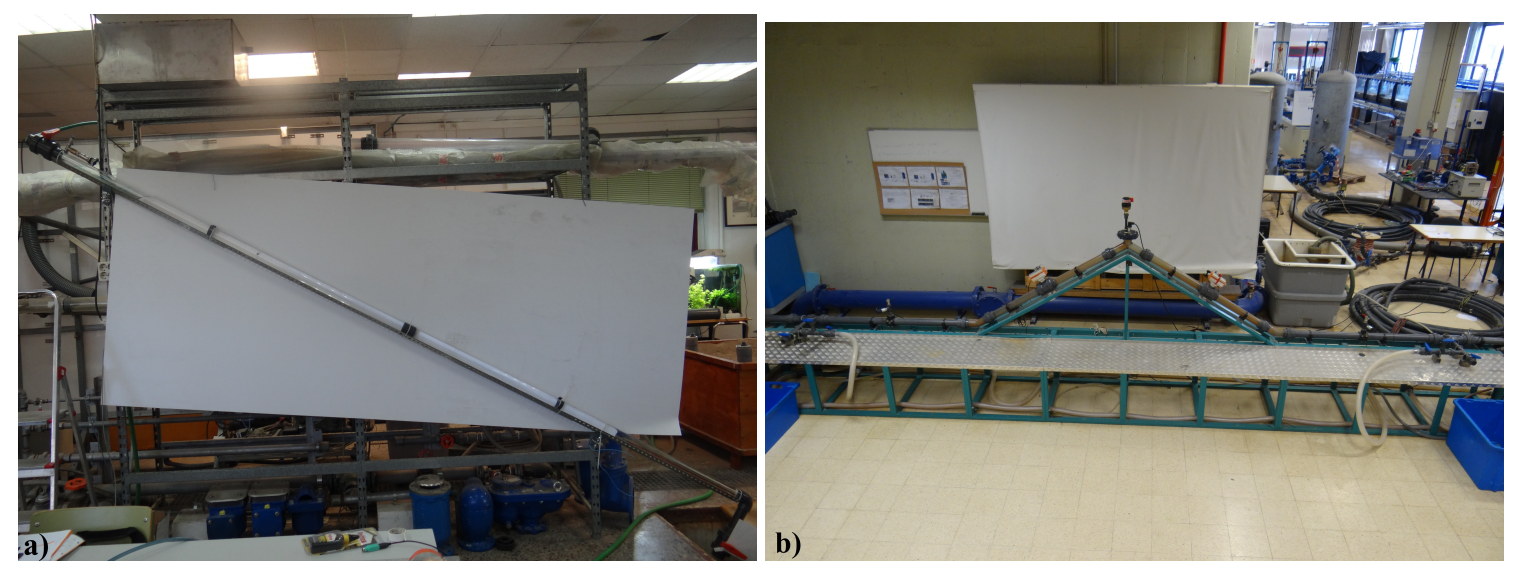

Figure 1. Experimental facilities to validate the emptying process: (a) single pipe (Universitat Politècnica de València, Spain). (b) pipeline of irregular profile (University of Lisbon, Portugal).

Pipe manufacturers suggest selecting the stiffness pipe as a function of the lowest value of sub-atmospheric pressure and others conditions of the pipe installations. Engineers select the stiffness class pipe based on their experiences. Another design feature is the selection of the air valve size for vacuum protection. The bigger the air valve size, the greater the protection of the system reached [6]. If air valves are improperly sized, the hydraulic event can damage not only the pipeline but also protection devices [1,16]. Drain valves maneuvers should be considered during the emptying process.

This research presents the mathematical model developed by the authors $[5,15]$ to analyze the emptying process, which was applied to the Ciudad del Bicentenario pipeline located in Cartagena, Bolívar Department, Colombia, in order to show the behavior of hydraulic and thermodynamic variables. The mathematical model can be used for engineers to conduct a water emptying process in pipelines in the design and planning stages to avoid the collapse of pipe systems.

\section{Pipeline Description}

The Ciudad del Bicentenario pipeline is located in the southern of the city of Cartagena, Bolívar Department, Colombia (see Figure 2). The company Aguas de Cartagena (Cartagena, Colombia) provided the entire information regarding the pipeline [17].

Figure 3 shows the scheme of the analyzed pipeline, which is located between chainages from $K 2+360 \mathrm{~m}$ to $K 2+940 \mathrm{~m}$. It is configured as a Glass-Reinforced Plastic (GRP) pipeline with nominal diameter of $1000 \mathrm{~mm}, 580 \mathrm{~m}$ long, pressure class of PN 10, and stiffness class of SN 5000 [18]. Slope branches vary in a range from $0 \%$ to $6.9 \%$. The system presents the emptying column No. 1 (chainages from $K 2+360 \mathrm{~m}$ to $K 2+620 \mathrm{~m}$ ), and the emptying column No. 2 (chainages from $K 2+940 \mathrm{~m}$ to $K 2+620 \mathrm{~m})$.

Three air valves were installed along the pipeline with nominal diameter of $100 \mathrm{~mm}$ (Type 9000-Pam manufacurer). They are located at chainages $K 2+360 \mathrm{~m}, K 2+700 \mathrm{~m}$, and $K 2+940 \mathrm{~m}$ (see Figure 3). Air valves should work in subsonic flow $(-0.3$ bar $<\Delta P<0)$ during the emptying process $[6,16]$. Using the formulation presented by Wylie and Streeter [13], the inflow discharge coefficient $\left(C_{a d m}\right)$ was calibrated with a value of 0.68 to get similar values to the data provided by the Pam manufacturer (Derbyshire, UK) [19] as shown in Figure 4. 

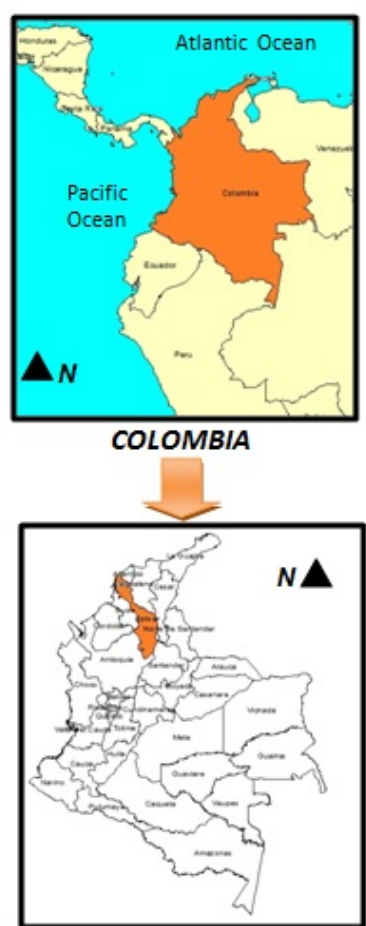

BOLIVAR DEPARTAMENT

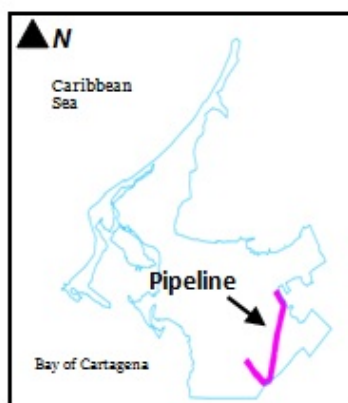

CIUDAD DEL BICENTENARIO PIPELINE

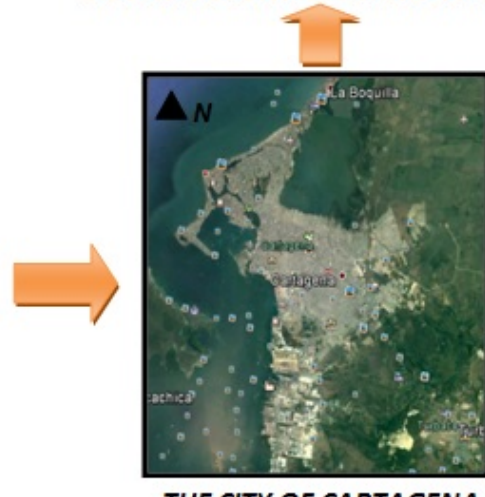

THE CITY OF CARTAGENA

Figure 2. Location of the Ciudad del Bicentenario pipeline.

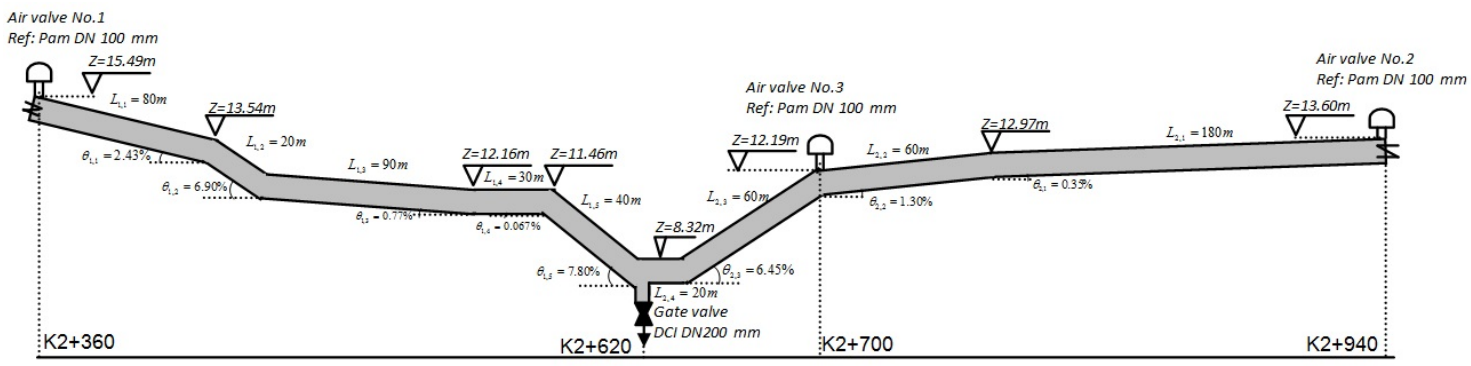

Figure 3. Profile-Ciudad del Bicentenario pipeline.

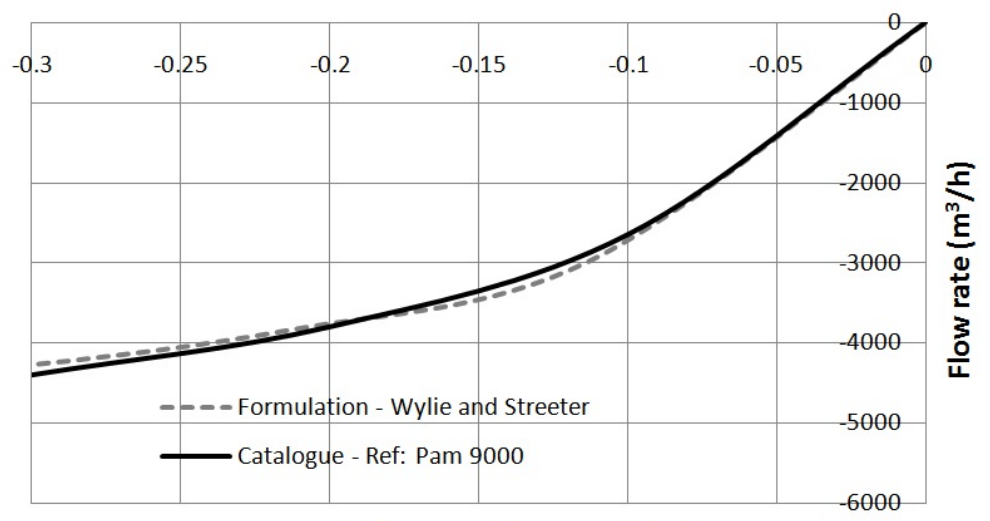

Differential pressure (bar)

Figure 4. Characteristics of the air valve-Type 9000 Pam manufacturer. 
A Ductile Cast Iron (DCI) gate valve with a nominal diameter of $200 \mathrm{~mm}$ was installed at chainage $K 2+620 \mathrm{~m}$ to drain the hydraulic system, with a resistance coefficient $\left(R_{v}\right)$ of $0.67 \mathrm{~ms}^{2} / \mathrm{m}^{6}$. A synthetic maneuver was considered with an opening time of $200 \mathrm{~s}$.

\section{Application of the Mathematical Model}

The emptying process was modeled based on formulations developed by the authors considered as the most critical condition when the pipeline is completely filled since it produces the lowest value of the sub-atmospheric pressure [5,15]. The mathematical model uses the following formulations: (i) rigid model to represent the water phase behavior $[3,5,15,20]$; (ii) a piston flow to describe the air-water interface [3-5,21]; (iii) a polytropic equation to describe the air phase behavior [22-24]; (iv) the continuity equation of the air pocket $[5,15]$; and (v) the air valve characterization [13] to quantify the admitted air volume.

\subsection{Equations}

The corresponding equations of the hydraulic system are:

1. Mass oscillation equation applied to the emptying column 1

$$
\frac{d v_{w, 1}}{d t}=\frac{p_{1}^{*}-p_{a t m}^{*}}{\rho_{w} L_{e, 1}}+g \frac{\Delta z_{e, 1}}{L_{e, 1}}-f \frac{v_{w, 1}\left|v_{w, 1}\right|}{2 D}-\frac{R_{v} g A^{2}\left(v_{w, 1}+v_{w, 2}\right)\left|v_{w, 1}+v_{w, 2}\right|}{L_{e, 1}}
$$

2. Emptying column 1 position

$$
\frac{d L_{e, 1}}{d t}=-v_{w, 1} \rightarrow L_{e, 1}=L_{e, 1,0}-\int_{0}^{t} v_{w, 1} \mathrm{~d} t
$$

3. Mass oscillation equation applied to the emptying column 2

$$
\frac{d v_{w, 2}}{d t}=\frac{p_{2}^{*}-p_{a t m}^{*}}{\rho_{w} L_{e, 2}}+g \frac{\Delta z_{e, 2}}{L_{e, 2}}-f \frac{v_{w, 2}\left|v_{w, 2}\right|}{2 D}-\frac{R_{v} g A^{2}\left(v_{w, 1}+v_{w, 2}\right)\left|v_{w, 1}+v_{w, 2}\right|}{L_{e, 2}},
$$

4. Emptying column 2 position

$$
\frac{d L_{e, 2}}{d t}=-v_{w, 2} \rightarrow L_{e, 2}=L_{e, 2,0}-\int_{0}^{t} v_{w, 2} \mathrm{~d} t
$$

5. Evolution of the air pocket 1

$$
\frac{d p_{1}^{*}}{d t}=\frac{p_{1}^{*} k}{\left(L_{1}-L_{e, 1}\right)}\left(\frac{\rho_{a, c n} Q_{a, c n, 1}}{A \rho_{a, 1}}-v_{w, 1}\right),
$$

6. Continuity equation of the air pocket 1

$$
\frac{d \rho_{a, 1}}{d t}=\frac{\rho_{a, n c} Q_{a, n c, 1}-v_{w, 1} A \rho_{a, 1}}{A\left(L_{1}-L_{e, 1}\right)},
$$

7. Air valve 1 characterization

$$
Q_{a, n c, 1}=C_{a d m} A_{a d m} \sqrt{7 p_{a t m}^{*} \rho_{a, n c}\left[\left(\frac{p_{1}^{*}}{p_{a t m}^{*}}\right)^{1.4286}-\left(\frac{p_{1}^{*}}{p_{a t m}^{*}}\right)^{1.714}\right]},
$$

8. Evolution of the air pocket 2

$$
\frac{d p_{2}^{*}}{d t}=\frac{p_{2}^{*} k}{\left(L_{2}-L_{e, 2}\right)}\left(\frac{\rho_{a, c n} Q_{a, c n, 2}+\rho_{a, c n} Q_{a, c n, 3}}{A \rho_{a, 2}}-v_{w, 2}\right),
$$


9. Continuity equation of the air pocket 2

$$
\frac{d \rho_{a, 2}}{d t}=\frac{\rho_{a, n c} Q_{a, n c, 2}+\rho_{a, n c} Q_{a, n c, 3}-v_{w, 2} A \rho_{a, 2}}{A\left(L_{2}-L_{e, 2}\right)},
$$

10. Air valve 2 characterization

$$
Q_{a, n c, 2}=C_{a d m} A_{a d m} \sqrt{7 p_{a t m}^{*} \rho_{a, n c}\left[\left(\frac{p_{2}^{*}}{p_{a t m}^{*}}\right)^{1.4286}-\left(\frac{p_{2}^{*}}{p_{a t m}^{*}}\right)^{1.714}\right]},
$$

11. Air valve 3 characterization

$$
Q_{a, n c, 3}=C_{a d m} A_{a d m} \sqrt{7 p_{a t m}^{*} \rho_{a, n c}\left[\left(\frac{p_{2}^{*}}{p_{a t m}^{*}}\right)^{1.4286}-\left(\frac{p_{2}^{*}}{p_{a t m}^{*}}\right)^{1.714}\right]}
$$

It is very important to note that air valves 1 and 2 are working all the time because they are located at the ends of the pipeline. However, air valve 3 only is working when the air pocket passes through the position $\mathrm{K} 2+700 \mathrm{~m}$.

A summary at set of describes the hydraulic and thermodynamic behavior of the emptying process, which can solved for the 11 unknown variables: $v_{w, 1}, v_{w, 2}, L_{e, 1}, L_{e, 2}, p_{1}^{*}, p_{2}^{*}, \rho_{a, 1}, \rho_{a, 2}, v_{a, c n, 1}$, $v_{a, c n, 2}$ and $v_{a, c n, 3}$.

\subsection{Initial and Boundary Conditions}

Considering the system is at rest $(t=0)$, then initial conditions are: $v_{w, 1}(0)=0, v_{w, 2}(0)=0$, $L_{e, 1}(0)=259 \mathrm{~m}, L_{e, 2}(0)=319 \mathrm{~m}, p_{1}^{*}(0)=101,325 \mathrm{~Pa}, p_{2}^{*}(0)=101,325 \mathrm{~Pa}, \rho_{a, 1}(0)=1.205 \mathrm{~kg} / \mathrm{m}^{3}$, $\rho_{a, 2}(0)=1.205 \mathrm{~kg} / \mathrm{m}^{3}, v_{a, c n, 1}(0)=0, v_{a, c n, 2}(0)=0$, and $v_{a, c n, 3}(0)=0$. The upstream boundary conditions are presented at chainages $K 2+360 \mathrm{~m}$ and $K 2+940$, where the air pockets 1 and 2 are at atmospheric conditions $\left(p_{a t m}^{*}\right)$. The downstream boundary condition is given by the opening of the gate valve (located at chainage $K 2+620)$, where the atmospheric pressure $\left(p_{a t m}^{*}\right)$ is presented by the free discharge.

\subsection{Gravity Term}

The gravity term of the emptying column 1 is computed by:

If $L_{1,1}+L_{1,2}+L_{1,3}+L_{1,4}+L_{1,5} \geq L_{e, 1}>L_{1,2}+L_{1,3}+L_{1,4}+L_{1,5}$, then:

$$
\frac{\Delta z_{1}}{L_{e, 1}}=\frac{L_{1,2} \sin \theta_{1,2}+L_{1,3} \sin \theta_{1,3}+L_{1,4} \sin \theta_{1,4}+L_{1,5} \sin \theta_{1,5}}{L_{e, 1}}+\left(1-\frac{L_{1,2}+L_{1,3}+L_{1,4}+L_{1,5}}{L_{e, 1}}\right) \sin \theta_{1,1},
$$

If $L_{1,2}+L_{1,3}+L_{1,4}+L_{1,5} \geq L_{e, 1}>L_{1,3}+L_{1,4}+L_{1,5}$, then:

$$
\frac{\Delta z_{1}}{L_{e, 1}}=\frac{L_{1,3} \sin \theta_{1,3}+L_{1,4} \sin \theta_{1,4}+L_{1,5} \sin \theta_{1,5}}{L_{e, 1}}+\left(1-\frac{L_{1,3}+L_{1,4}+L_{1,5}}{L_{e, 1}}\right) \sin \theta_{1,2}
$$

If $L_{1,3}+L_{1,4}+L_{1,5} \geq L_{e, 1}>L_{1,4}+L_{1,5}$, then:

$$
\frac{\Delta z_{1}}{L_{e, 1}}=\frac{L_{1,4} \sin \theta_{1,4}+L_{1,5} \sin \theta_{1,5}}{L_{e, 1}}+\left(1-\frac{L_{1,4}+L_{1,5}}{L_{e, 1}}\right) \sin \theta_{1,3}
$$

If $L_{1,4}+L_{1,5} \geq L_{e, 1}>L_{1,5}$, then:

$$
\frac{\Delta z_{1}}{L_{e, 1}}=\frac{L_{1,5} \sin \theta_{1,5}}{L_{e, 1}}+\left(1-\frac{L_{1,5}}{L_{e, 1}}\right) \sin \theta_{1,4},
$$


If $L_{1,5} \geq L_{e, 1}>0$, then:

$$
\frac{\Delta z_{1}}{L_{e, 1}}=\sin \theta_{1,5}
$$

The gravity term of the emptying column 2 is computed by:

If $L_{2,1}+L_{2,2}+L_{2,3}+L_{2,4} \geq L_{e, 2}>L_{2,2}+L_{2,3}+L_{2,4}$, then:

$$
\frac{\Delta z_{2}}{L_{e, 2}}=\frac{L_{2,2} \sin \theta_{2,2}+L_{2,3} \sin \theta_{2,3}}{L_{e, 2}}+\left(1-\frac{L_{2,2}+L_{2,3}+L_{2,4}}{L_{e, 2}}\right) \sin \theta_{2,1},
$$

If $L_{2,2}+L_{2,3}+L_{2,4} \geq L_{e, 2}>L_{2,3}+L_{2,4}$, then:

$$
\frac{\Delta z_{2}}{L_{e, 2}}=\frac{L_{2,3} \sin \theta_{2,3}}{L_{e, 2}}+\left(1-\frac{L_{2,3}+L_{2,4}}{L_{e, 2}}\right) \sin \theta_{2,2}
$$

If $L_{2,3}+L_{2,4} \geq L_{e, 2}>L_{2,4}$, then:

$$
\frac{\Delta z_{2}}{L_{e, 2}}=\left(1-\frac{L_{2,4}}{L_{e, 2}}\right) \sin \theta_{2,3}
$$

If $L_{2,4} \geq L_{e, 2}>0$, then:

$$
\frac{\Delta z_{2}}{L_{e, 2}}=0
$$

\section{Results and Discussion}

The resolution of this set of differential-algebraic equations (Equations (1)-(11)) was conducted using Matlab (The MathWorks, Inc., Natick, MA, USA). In order to simulate the most critical situations, small air pocket sizes were considered. However, to avoid a numerical problem, a minimum air pocket length of $1 \mathrm{~mm}$ was established in water columns 1 and 2 [5]. A friction factor of 0.011 was used considering an absolute roughness $k_{s}$ of $0.029 \mathrm{~mm}$ and a polytropic coefficient $(k)$ of 1.2.

\subsection{Absolute Pressure and Air Pocket Density}

In the air pocket 1 , the minimum sub-atmospheric pressure head occurs at $249.4 \mathrm{~s}$ with a value of $8.48 \mathrm{~m}$ (negative pressure of $-1.85 \mathrm{~m}$ ), which is reached after of the total opening of the gate valve (see Figure 5). On the other hand, in air pocket 2, the minimum value was $8.96 \mathrm{~m}$ (negative pressure of $-1.37 \mathrm{~m}$ ) at $125.1 \mathrm{~s}$, which occurs because the quantity of admitted air by air valve 2 is not enough. However, when the air valve 3 starts to admit air into the system, then the absolute pressure pattern rises in the air pocket 2. At the end of the hydraulic event, emptying columns 1 and 2 reach the atmospheric conditions $\left(p_{a t m}^{*}\right)$. The minimum values of the sub-atmospheric pressure were checked by technical personnel during the emptying process of the pipeline.

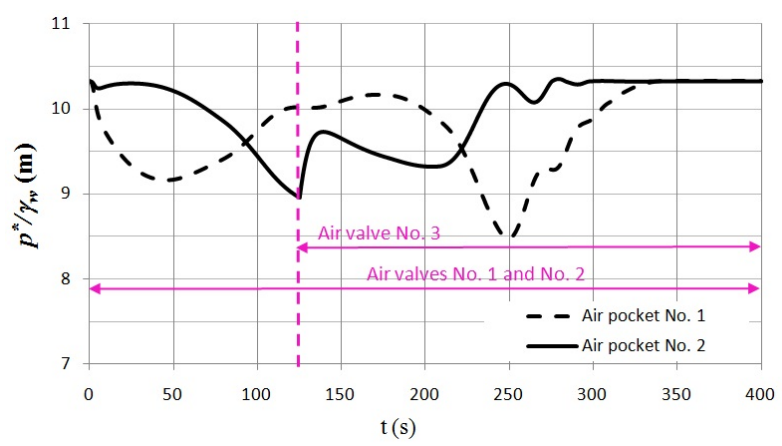

Figure 5. Evolution during the hydraulic event of the absolute pressure of the air pocket. 
The evolution of the air pocket density exhibits a parallel behaviour to the absolute pressure pattern as expected for the polytropic model (Equations (5) or (8)) and the formulation of ideal gas law [21] $\left(p^{*}=\rho_{a} R T_{a}\right)$.

\subsection{Length of the Emptying Columns}

Transient phenomenon shows how the lengths of the emptying columns 1 and 2 are drained during the entire hydraulic event, as a consequence of admitted air by air valves into the system (see Figure 6). The emptying column 1 is drained completely at 338.9 s, whereas the emptying column 2 cannot drain completely due to horizontal branch of $20 \mathrm{~m}$ long located the end, which drains more slowly, and part of the water column can remain inside of the installation.

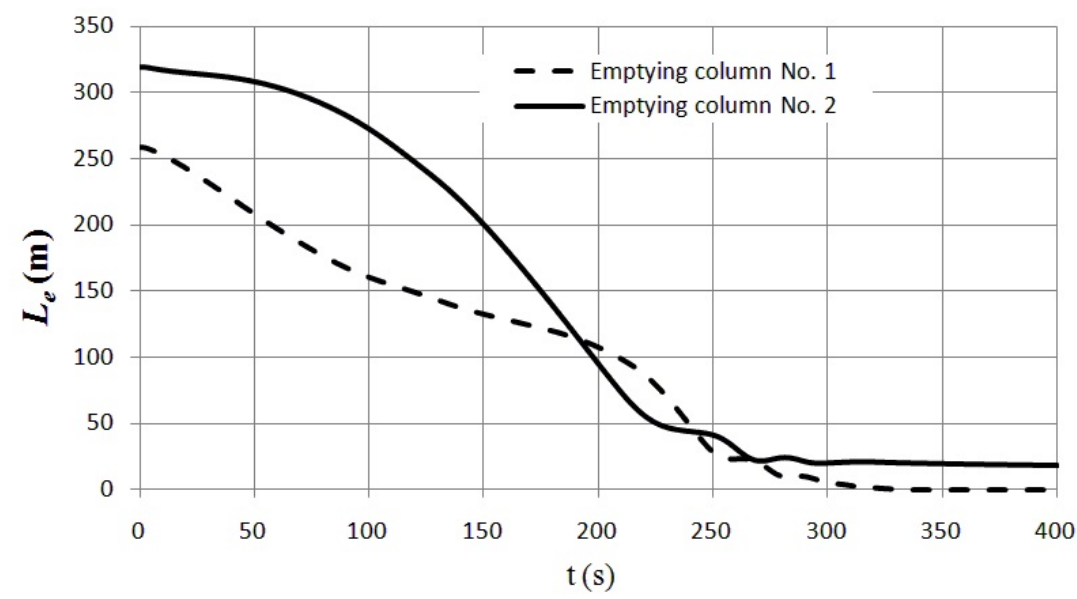

Figure 6. Evolution during the hydraulic event of the length of the emptying columns.

\subsection{Water and Air Flow of Emptying Columns}

Figure 7 presents the evolution of the water and air flow for the emptying column 1 where, during the first $157.2 \mathrm{~s}$, the water volume drained is practically the same as the air volume admitted by the air valve 1. During this time, the sub-atmospheric pressure head values are higher than $9.17 \mathrm{~m}$. The minimum value of $8.48 \mathrm{~m}$ (at $249.3 \mathrm{~s}$ ) of the absolute pressure head is reached after the total opening of the gate valve $\left(T_{m}=220 \mathrm{~s}\right)$. The water flow surpasses the air flow generating the trough of the sub-atmospheric pressure aforementioned. At the end, some oscillations occur because the air flow is greater than water flow.

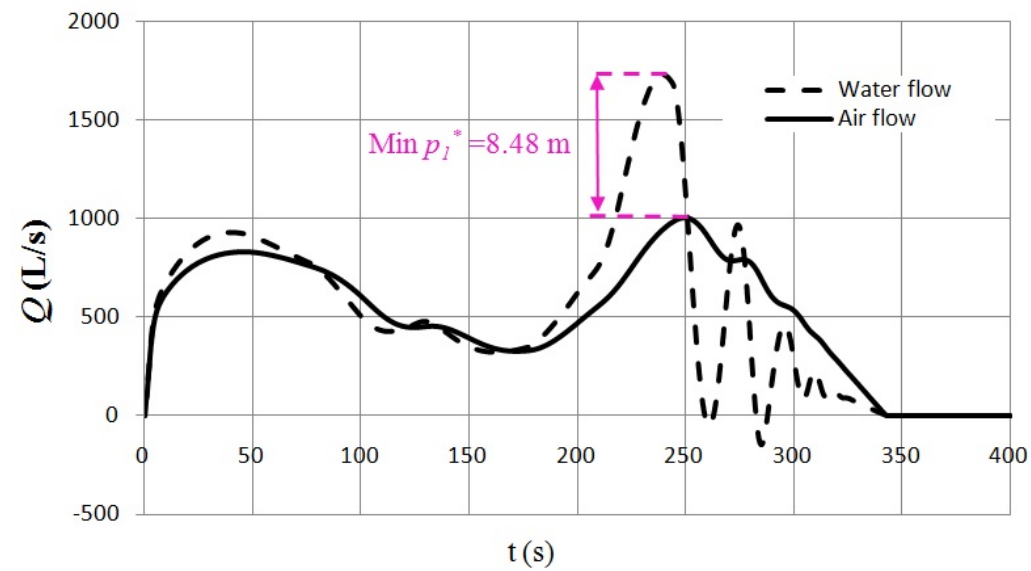

Figure 7. Evolution of the water and air flow in the emptying column 1. 
Figure 8 shows the behaviour of the water and air flow in the emptying column 2 . At the beginning of the hydraulic event (from $0 \mathrm{~s}$ to $54 \mathrm{~s}$ ), air valve 2 can introduce enough quantity of air volume adequately, where the water and air flow are similar with values of $325.6 \mathrm{~L} / \mathrm{s}$ and $311.4 \mathrm{~L} / \mathrm{s}$, respectively. Then, from $54 \mathrm{~s}$ to $125 \mathrm{~s}$, the water flow surpasses the air flow. The minimum value of $8.96 \mathrm{~m}$ of sub-atmospheric pressure head is reached at $125 \mathrm{~s}$, when air valve 3 starts to relieve the sub-amospheric pressure occurrence avoiding the risk of collapse of the installation at least until 132.7 s. At $201.2 \mathrm{~s}$, air valves 2 and 3 cannot admit the required air volume generating another trough of sub-atmospheric pressure of $9.32 \mathrm{~m}$. At the end, some oscillations occur similarly to emptying column 1.

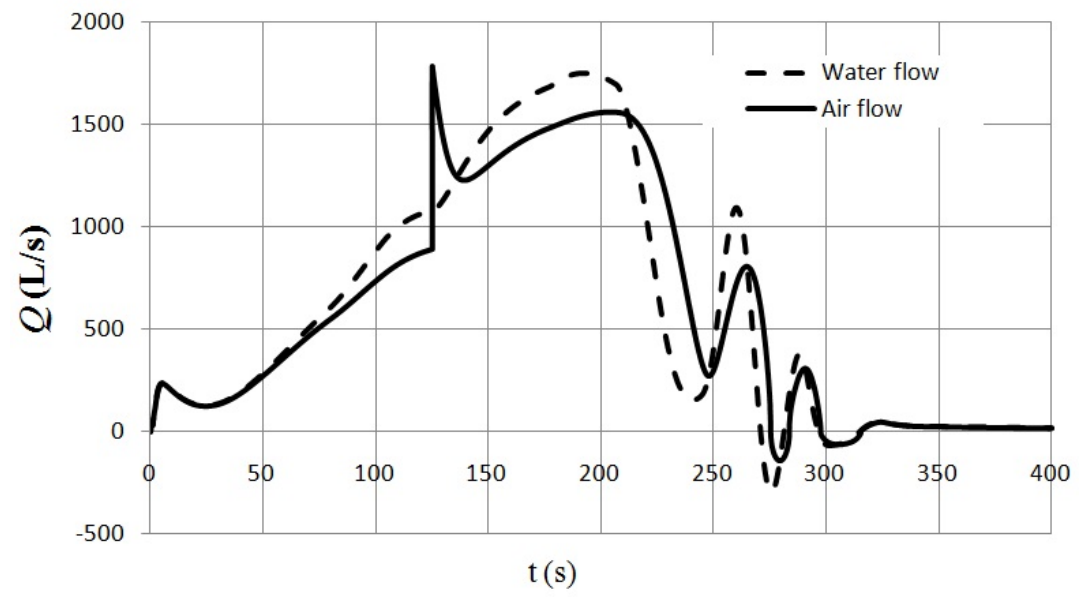

Figure 8. Evolution of the water and air flow in emptying column 2.

\subsection{Risk of Pipeline Collapse}

According to the pipe manufacturer, the stiffness class of a pipeline should be selected considering two parameters: (i) burial conditions, which include the soil in natural conditions, the type of backfill, and the cover depth; and (ii) the minimum value of the sub-atmospheric pressure. The analyzed GRP pipeline (Amiantit Pipe Systems, Dammam, Saudi Arabia) of nominal $1000 \mathrm{~mm}$ diameter and stiffness class of $S N 5000$ can support a sub-atmospheric pressure value of $7.78 \mathrm{~m}$ (negative pressure of -0.25 bar or $-2.55 \mathrm{~m}$ ) considering a cover depth of $10 \mathrm{~m}$, and a typical type of backfill and a soil in natural conditions. During the emptying process, the minimum value of $8.48 \mathrm{~m}$ (or $-0.18 \mathrm{bar}$ ) is reached at $249.3 \mathrm{~s}$ with a depth of $5.75 \mathrm{~m}$ according to construction drawing, which is lower than the values aforementioned. As a consequence, there is not a risk of collapse of the installation after checking that air valves and the operation of the gate valve are adequate.

Figure 9 presents the minimum values of sub-atmospheric pressure depending on the failure of air valves 1, 2, or 3. Four zones are identified. Zone $I$ is presented when both the air valves are working or air valve No. 3 fails. Then, the hydraulic system is completely protected from the sub-atmospheric pressure occurrence and there is no risk of collapse. Zones $I I$ and $I V$ are characterized for the failure of the air valves located at the ends. If air valve No. 1 fails, then air pocket 1 can cause the collapse of branch pipe 1 with a value of sub-atmospheric pressure head of $3.20 \mathrm{~m}$; and if air valve No. 2 fails, then the minimum value of the sub-atmospheric pressure head is $4.90 \mathrm{~m}$ in branch pipe 2 . The most critical condition is presented in Zone $I I I$, when the air valves fail. Branch pipes 1 and 2 can collapse with values of sub-atmospheric pressure head of $2.15 \mathrm{~m}$ and $4.18 \mathrm{~m}$, respectively. Good maintenance of air valves is crucial in order to minimize risk of collapse of pipelines during the emptying process. 


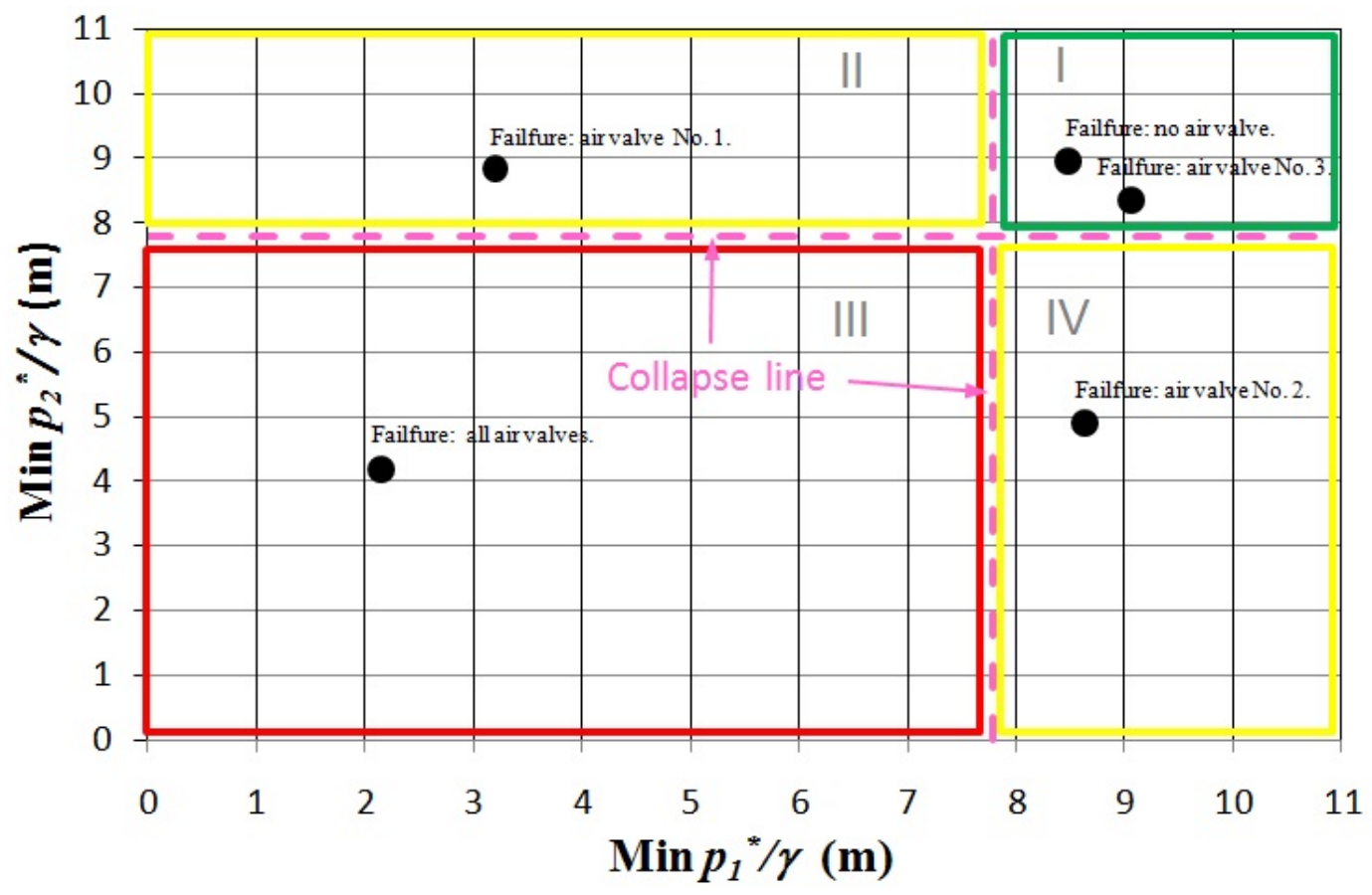

Figure 9. Sensitivity analysis regarding the failure of air valves.

\section{Conclusions}

This research presents both the mathematical model to simulate the emptying operation in water supply networks and the application to the Ciudad del Bicentenario pipeline located in Cartagena, Colombia. The analyzed pipeline has a nominal diameter of $1000 \mathrm{~mm}$ and $580 \mathrm{~m}$ long. The entire information about the pipeline was supplied by Aguas de Cartagena, which operates the water supply network in Cartagena, Colombia. The mathematical model gives important information regarding the main hydraulic and thermodynamic variables (water velocities, length of the water columns, air densities, absolute pressure of air pockets, and air flows).

Regarding to the application of the mathematical model, the following conclusions can be drawn:

- The mathematical model can be used for computing air valve sizes, maneuvering drain valves, and knowing the drainage time of pipelines to prevent the collapse of the hydraulic system.

- The minimum value of sub-atmospheric pressure is one of the most critical situations during the emptying process, which is adequately predicted by the mathematical model.

- $\quad$ Air valves should be selected appropriately along the pipe systems admitting the required air to avoid sub-atmospheric pressure conditions. If air valves have not been well sized, then extreme negative pressures are reached, which can cause the collapse of pipe systems. The mathematical model can be used to check the air valves behaviour during the emptying maneuvers in actual installations.

- The Ciudad del Bicentenario pipeline can resist the minimum value of sub-atmospheric pressure showing that there is no risk of collapse since the total volume of admitted air is similar to the volume of drained water. Both air valve sizes and the maneuver of the gate valve were adequately designed, so they can be used to empty the pipeline without risk of collapse. Annual maintenance is required for the air valves located at the ends of the installation since a failure of these devices can cause the collapse of branch pipes according to the sensitivity analysis.

- Horizontal branches in pipelines are not recommended because part of the water column can remain inside of the installation and free surface flow is presented, generating a slow drainage of the system.

This research only analyzed the risk of pipeline collapse during the emptying process. However, other sources of sub-atmospheric pressure occurrence should be analyzed (e.g., pumps' stoppages). 
Acknowledgments: The authors acknowledge the financial support for Oscar E. Coronado-Hernández covered by Fundación Centro de Estudios Interdisciplinarios Básicos y Aplicados (CEIBA)—Gobernación de Bolívar (Colombia).

Author Contributions: Oscar E. Coronado-Hernández and Vicente S. Fuertes-Miquel wrote the entire paper and applied the mathematical model, and Fredy N. Angulo-Hernández provided the entire information about the analyzed pipeline.

Conflicts of Interest: The authors declare no conflict of interest.

\section{Abbreviations}

The following abbreviations are used in this manuscript:

$A$
$A_{a d m}$
$C_{a d m}$
$D$
$f$
$g$
$L_{e, 1}$ and $L_{e, 2}$
$L_{1}$ and $L_{2}$
$L_{i, j}$
$k$
$p_{1}^{*}$ and $p_{2}^{*}$
$p_{a t m}^{*}$
$R$
$R_{v}$
$t$
$T_{a}$
$Q_{a, n c, 1}, Q_{a, n c, 2}$ and $Q_{a, n c, 3}$
$v_{w, 1}$ and $v_{w, 2}$
$\rho_{a, 1}$ and $\rho_{a, 2}$
$\rho_{a, n c}$
$\rho_{w}$
$\Delta z_{e, 1}$ and $\Delta z_{e, 2}$
$\theta_{i, j}$

cross-sectional area of pipe $\left(\mathrm{m}^{2}\right)$;

cross sectional area of the air valves $\left(\mathrm{m}^{2}\right)$;

inflow discharge coefficient of the air valves (-);

internal pipe diameter $(\mathrm{m})$;

friction factor $(-)$;

gravity acceleration $\left(\mathrm{m} / \mathrm{s}^{2}\right)$;

length of emptying columns 1 and 2, respectively (m);

total length of pipes 1 and 2, respectively (m);

branch length $i, j(\mathrm{~m})$;

polytropic coefficient (-);

absolute pressure of air pockets 1 and 2, respectively $(\mathrm{Pa})$;

atmospheric pressure $(\mathrm{Pa})$;

gas constant $\left(\mathrm{J} / \mathrm{kg} /{ }^{\circ} \mathrm{K}\right)$;

resistance coefficient of the gate valve $\left(\mathrm{s}^{2} / \mathrm{m}^{5}\right)$;

time (s);

absolute temperature of the air $\left({ }^{\circ} \mathrm{K}\right)$

admitted air flow by air valves 1,2 , and 3 , respectively $\left(\mathrm{m}^{3} / \mathrm{s}\right)$;

water velocity of emptying columns 1 and 2 , respectively $(\mathrm{m} / \mathrm{s})$;

air density of air pockets 1 and 2, respectively $\left(\mathrm{kg} / \mathrm{m}^{3}\right)$;

air density in normal conditions $\left(\mathrm{kg} / \mathrm{m}^{3}\right)$;

water density $\left(\mathrm{kg} / \mathrm{m}^{3}\right)$;

difference elevation of water columns 1 and 2, respectively;

branch slope $i, j$

\section{References}

1. Apollonio, C.; Balacco, G.; Fontana, N.; Giugni, M.; Marini, G.; Piccinni, A.F. Hydraulic Transients Caused by Air Expulsion During Rapid Filling of Undulating Pipelines. Water 2016, 8, 25.

2. Balacco, G.; Apollonio, C.; Piccinni, A.F. Experimental Analysis of Air Valve Behaviour During Hydraulic Transients. J. Appl. Water Eng. Res. 2015, 3, 3-11.

3. Izquierdo, J.; Fuertes, V.S.; Cabrera, E.; Iglesias, P.; García-Serra, J. Pipeline start-up with entrapped air. J. Hydraul. Res. 1999, 37, 579-590.

4. Zhou, L.; Liu, D.; Karney, B. Investigation of hydraulic transients of two entrapped air pockets in a water pipeline. J. Hydraul. Eng. 2013, 139, 949-959.

5. Coronado-Hernández, O.E.; Fuertes-Miquel, V.S.; Besharat, M.; Ramos, H.M. Experimental and Numerical Analysis of a Water Emptying Pipeline Using Different Air Valves. Water 2017, 9, 98.

6. American Water Works Association (AWWA). Manual of Water Supply Practices-M51: Air-Release, Air-Vacuum, and Combination Air Valves; American Water Works Association: Denver, CO, USA, 2001.

7. Ramezani, L.; Karney, B.; Malekpour, A. The Challenge of Air Valves: A Selective Critical Literature Review. J. Water Resour. Plan. Manag. 2015, 141, 10 .

8. Covas, D.; Stoianov, I.; Ramos, H.M.; Graham, N.; Maksimovic̀, C.; Butler, D. Water hammer in pressurized polyethylene pipes: Conceptual model and experimental analysis. Urban Water J. 2010, 1, 177-197. 
9. Martins, S.C.; Ramos, H.M.; Almeida, A.B. Conceptual analogy for modelling entrapped air action in hydraulic systems. J. Hydraul. Res. 2015, 53, 678-686.

10. Pozos-Estrada, O.; Sánchez-Huerta, A.; Breña-Naranjo, J.; Pedrozo-Acuña, A. Failure analysis of a water supply pumping pipeline system. Water 2016, 8, 395.

11. Abreu, J.; Cabrera, E.; Izquierdo, J.; García-Serra, J. Flow Modeling in Pressurized Systmes Revisited. J. Hydraul. Eng. 1999, 125, 1154-1169.

12. Escarameia, M. Air Problems in Pipelines: A Design Manual; HR Wallingford Ltd.: Wallingford, UK, 2005.

13. Wylie, E.; Streeter, V. Fluid Transients in Systems; Prentice Hall: Englewood Cliffs, NJ, USA, 1993.

14. Bianchi, A.; Mambretti, S.; Pianta, P. Practical formulas for the dimensioning of air valves. J. Hydraul. Eng. 2007, 133, 1177-1180.

15. Fuertes-Miquel, V.S.; Coronado-Hernández, O.E.; Iglesias-Rey, P.L.; Mora-Melia, D. Transient phenomena during the emptying process of a single pipe with water-air interaction. J. Hydraul. Res. 2017, accepted.

16. Ramezani, L.; Karney, B.; Malekpour, A. Encouraging Effective Air Management in Water Pipelines: A Critical Review. J. Water Resour. Plan. Manag. 2016, 142, 12.

17. Aguas de Cartagena. Construction drawing of the "Conducción agua potable Ciudad del Bicentenario Planta-Perfil K2+500.35 al K3+160.00". 2013.

18. Flowtite Technology. Product Guide-Amiantit Fiberglass Industries Limited (AFIL); Amiantit: Dammam, Saudi Arabia, 2008.

19. Saint-Gobain. 612 Potable Water-Double Orifice Air Valve; Saint-Gobain Pam: Derbyshire, UK, 2009.

20. Fuertes-Miquel, V.S.; López-Jiménez, P.A.; Martínez-Solano, F.J.; López-Patiño, G. Numerical modelling of pipelines with air pockets and air valves. Can. J. Civ. Eng. 2016, 43, 1052-1061.

21. Zhou, L.; Liu, D.; Karney, B. Phenomenon of white mist in pipelines rapidly filling with water with entrapped air pocket. J. Hydraul. Eng. 2013, 139, 1041-1051.

22. Martin, C.S. Entrapped air in pipelines. In Proceedings of the Second International Conference on Pressure Surges; British Hydromechanics Research Association: London, UK, 1976.

23. Graze, H.R.; Megler, V.; Hartmann, S. Thermodynamic behaviour of entrapped air in an air chamber. In Proceedings of the 7th International Conference on Pressure Surges and Fluid Transients in Pipelines and Open Channels; Boldy, A.P., Ed.; Mechanical Engineering Publications: New York, NY, USA, 1996; pp. 549-560.

24. Leon, A.; Ghidaoui, M.; Schmidt, A.; Garcia, M. A robust two-equation model for transient-mixed flows. J. Hydraul. Res. 2010, 48, 44-56.

(C) 2017 by the authors. Licensee MDPI, Basel, Switzerland. This article is an open access article distributed under the terms and conditions of the Creative Commons Attribution (CC BY) license (http:// creativecommons.org/licenses/by/4.0/). 